\title{
MARKSIZMIN GÜNÜMÜZDE GEÇERLIĞI
}

\author{
Prof. Dr. Cem EROĞUL
}

Sovyetler Birliģi'yle birlikte, Marksizm de çöktü mü?

Batı'dan kaynaklanan ve bütün dünyada yankılanan egemen düşüngüye (iđeolojiye) bakılırsa: Evet. Çünkü Marksizm, belli bir devletin genörgütsel (bürokratik) çıkarlarına geçerlik kazandırmak için kullanılan bir kılıftı. Devlet yıkılınca, bu kılıfın da yırtılmış olması dogaldır. Kaldı ki Marx, bir bilim adamından çok, kafası karışı bir filozof ve hırsh bir eylemciydi. Bilimscl öngörü diye ileri sürdügü şeylerin hiçbiri gerçckleşmemiştir: ne işçi sınıfı hızla yoksullaşıp düzeni devirmeye kalkışmışır, ne de kapitalizm kendi iç çeliş̧ileriyle çökmüş̧ür. Aksine, iş̧̧i sınıfı gitgide burjuvalaşmışur. Kapitalizm ise, gü̧̧lüklcrini aşmakla kalmamış, bilimin ve yordamın (tcknił̧in) gelişmesi için en elverişli çerçeveyi yaratmasını bilmiştir. Sonuçta, Marksizmi bayrak edinen siyasal düzenler cvrensel yarışıa kesinlikle yenilmişler, onlar da, dünyanın geri kalan bőlümü gibi, kurtuluşun ancak piyasa gü̧̧lerine bütünüyle teslim olmakta bulunabileceğini anlamışlardır.

$\mathrm{Bu}$ savların geçerliłgini tartabilmek, dolayısıyla da, Marksizmin bugün için bir anlam taşıyıp taşımadığını saptayabilmek için, konuyu dizgesel (sistematik) bir biçimde çözümlemek gerekir. Bu amaçla, aşă̌̆ıda, Marksizmin felsefe, bilim ve siyaset yönleri, ayrı ayn ele alınacakur.

\section{MARKSIZM VE FELSEFE}

Bir felsefe olarak Marksizm, "diyalcktik maddecilik" olarak bilinir. Diyalektiğin olsun maddeciliżin olsun, kökeni Eski Yunan'a dayanır. Gerçekten de, yaşamın temel yasasının sınırsız bir dç̧işim olduğunu savunduğu için ilk diyalcktikçi olarak bilinen Efcsli Heraklcitos, 1.O. altıncı yüzyılda yaşamıştır. Varlığın büttünüyle madde parçacıklarından ("atom"lardan) oluşıģunu savunan ilk maddeci, Abderalı (Trakyalı) Demokritos da, l.Ö. beşinci yüzyılda yaşamıştır. Yani, düşünsel ürünler olarak, diyalektiğin de, maddeciliģin de tarihi çok eskidir.

Marx ile Engels, kendilerinden önceki bu uzun sürècin son halkalan olan Hegel (diyalektikçi) ile Feuerbach'tan (maddeci) esinlenerek, bu iki akımı özgün bir biçimde 
birleştirmişlerdir. Savunduklan dünya görüşü şöyle özetlenebilir: Insan bilincinin dışında bir gerçek vardır. Bu gerçeģi yaratan insan bilinci değildir. Aksine, bilincin kendisi, bu maddi gerçeģin ürünüdür. Oyle olduğu içindir ki, insan, gerçeği tanıabilir. Ancak, bunun için, insan bilincinin, gerçeğin temél ozelliklerini yansıtacak biçimde işlemesi gerekir. Bu temel ózellikler ise şöyle sıralanabilir: Var olan her şey, sürekli bir devinim (hareket), sürekli bir deģişim içindedir. Bu devinim, bu deģişim, sonsuz çeşitte ortaya çıkar. Maddenin çeşitliliğini de, işte bu devinim, deģişim çeşitliliği açıklar. Her devinim, her deģişim, ayn bir çeliş̧inin ürünüđür. Çelişkiler aşıldıkça, durmadan yenileri oluşur. Bu da, devinimin, deģişimin, hep sürmesine yol açar. Varlığı oluşturan bu sonsuz sayıdaki süreç, iç içe geçmiş durumdadır. Dolayısıyla, her şey her şeyi ckkiler. Bu sürekli devinimin, deģişimin, onceden belirlenmiş bir yönü yoktur. Süreçlerin iç çelişkileri ve karşılıkl etkileşimleri sonucunda, zaman zaman dönüşümler (devrimler) ortaya çıkar. Işte bu nitel sıçramalara bakarak, her sürecin ne gibi basamaklardan geçtiği, dolayısıyla da ne yönde geliştigi kestirilebilir.

Marx ile Engels, klasik anlamda felsefenin, yani dizgeler (sistemler) yaratan felsefelerin, Hegel'le birlikte doruğa eriştigini ve bittigini, artık bu anlamda bir felsefeye yer kalmadığını düşünüyorlardı. Çünkü, felsefe dizgelerini, bilimlerin burakı̆ğı boşluklan doldurmaya çalışan kurgusal (spekülatif) çabalar olarak deģerlendiriyorlardı. Doğa bilimlerinde, kendi zamanlarına dek gerçekleştirilen temel buluşlar sayesinde, aruk böyle kurgularla doldurulacak büyük boşluklar kalmadığı kanısına varmışlardı. Işı bu nedenle, kurguya dayanan felsefe dizgelerinin çağının kapandığı görüşündeydiler.

Bu, felsefenin sonu muydu? Klasik biçimiyle, evet. Bilimsel biçimiyle ise, hayır. Ancak, felsefenin "bilimsel biçimi" ne demekti? Bu anlayışa göre, bundan böyle felsefenin temel işlevi, gitgide uzmanlaştıkları için doğanın ve toplumun genel akışını gözden kaçırma tehlikesiyle karşı karşıya kalan türlü bilim dallarına ışı tutmaktır. Diyalektik maddecilik, felsefenin bu yeni bilimsel biçiminin adıdır.Marx ile Engels'in geliştirdikleri görüşe göre, kendi üzerine düşen bu yeni görevi yerine getircbilmek için felsefenin "olmazsa olmaz" nitelik koşulu, sürekli olarak bilimsel gelişmeleri yakından izlemektir. Ancak bunu yapan bir felsefe, türlü bilim dalları arasındaki kesişme noktaların, ortak sorunları, beliren genel eğilimleri, vb. saptayabilir ve bunlan tüm bilim adamlarının dikkatine sunabilir.

Marx ile Engels'in geliştirdikleri bu yeni felsefe anlayışına ilişkin olarak neler söylenebilir?

Bir kere, bu anlayışta, felsefenin büyük harfle yazılan birtakım temel kavramlarına yer kalmamışur. Varłık, Madde, Ruh, Bilgi, Insan,Öte đünya vb. kavramlar, tartı̧̧a konusu olmaktan çıkmıştır. Genel soyut kavramlar ("kategoriler") üzerinde yürütülen kurgusal bir çaba olarak felsefenin dőnemi kapanmıştır. Bunun yerini, bir dizi somut bilimsel araşurmanın ortak yőnlerini yakalamaya çalışan bir soyutlama çabası almışııı. Gerçi bu yeni yaklaşımda da kavramlar vardır. Ancak artık bunlar, genel' soyut kurguların ürünü deł̧il, bin bir somut deneyden süzülen soyutlamalardır. Onun için bunlar, kesinlikle birer düşsel kalıp olarak değil, gerçeklerin birer genel özeti olarak görülmelidir.

Ikincisi, on dokuzuncu yüzyıldan beri bilimlerde ortaya çıkan eşsiz ilerleme, duragan mantuğın ("metafizik" mantığı) da, felsefi "idealizmin" de savunulmasını neredeyse olanaksız kılmışıtır. Bugün bilim alanında çalışıp her şeyin her şeyi etkiledił̧ini, gerçeklerin sürekli bir dőnüşüm içinde olan bir çelişkiler yumağı 
oluşturduğunu, uzaya gidecek ölçüde etkilediğimiz bir dünyayı tanıyıp tanıyamayacağımızı sormanın arık anlamsız kaldığını, kabul etmeyen yoktur. Başka bir deyişle, diyalektik maddecilik, aruk gitgide genel "sağduyu" gereği olmaktadır.

Üçüncüsü, diyalcktik maddecilik sağduyu ile iç içe geçtikçe, savundư̆u görüşler de gitgide daha "basit" gőrünmektedir. Her şeyin sürekli bir devinim içinde olduğu, ya da her şcyin her şeyi etkiledił̧i gibi ilkeler, neredeyse "apaçık" gerçekler durumuna gelmektedir. Bu sıradanlaşmanın bir yozlaşmaya dönüşmemesi için diyalektik maddeciliğin yapacağı şey, yeni sał̆duyunun tutarlı olması gereğine işaret etmektir. Ömeğin, "Dünyayı biz yeniden yaratabiliyorsak, yaratıcı bir Tanrı görüşü hâlâ savunulabilir mi? ya da "Her şey değişip dönüşmeye yazgılı ise, piyasaya dayanan geçim düzeninin de geçici oldugunu kabul etmek gerekmez mi?" gibi: Görüldü̈ü gibi, belirtilen bu anlamıyla "Marksist felscfe", sağduyuyla birleş̧iği ölçüde, genel bir bilinçlendirme işlevi yüklenmektedir.

Dördüncüsü, diyalektik maddeciliğin geliştirdiği soyutlamaların, eski felsefe dizgelerinin gencl soyut kavramlan gibi düşünülmesi tehlikesi daima vardır. Marksizm'in bir felsefe olarak karşıllaşı̆gı en büyük tehdit budur. Işin ilginç yönü ise, gerçek yaşamda bu tehlikenin, Marksizmi resmen savunan sosyalist ülkelerde en büyük boyutlara erişmiş glmasıdır. Diyalektik maddeciliłin gözleme dayanan birtakım soyutlamalan, büyük harfli Yasalar, tlkeler durumuna getirilmiş, böylece klasik felsefenin soyutluk anlayışına dőnülmüştür. Artık "bilimsel" olduģunu da yüksek sesle savunan bu yeni felsefe dizgesinde, "bilimlerden öğrenerek onlara ışı tutma çabası", "bilimlerin üzerinde sulta kurma" tutuculuğuna dönüşmüştür. Bu yoldan, Marksizmin hiçbir felsefe "dizgesinin" bilimsel olamayacağı, ancak kurgusal olacağı görü̧̧̧ü hiçe sayılarak, devrimci düşüncenin alın anahtan olarak geliştirilmiş olan diyalektik maddecilik, üstelik Marx'ın adı da dillerden düşürülmeden, kaba bir tutuculựun aracı olmaya sürüklenebilmiştir.

Diyalektik maddeciliğe ilişkin olarak yapılan bu gözlemlerden şoyle bir sonuca ulaşılabilir: "Marksișt felsefe" ölmez; çünkü bu felsefe, kapalı bir dizge değil, kendini içsel olarak bilimlerin gelişmesine bağlamış, dolayısıyla da somut içeriği daima yenilenmesi gereken bir dizgeli düşünme çabasıdır. Marksist felsefeyi öldürebilecek tek şey, bu dışa açık çabanın dondurulması, bilimierden ögrenmeden onlara yol gösterme bilgiçliğine baulmasıdur.

\section{MARKSIZM VE BILIM}

Bir bilim dalı olarak Marksizm, kendisini "tarihsel maddecilik" olarak adlandırmışır. "Tarihsel" burada "toplumsal" anlamına gelmektedir; ancak deģişim, dönüşüm, süreç yönü vurgulanmış bir toplumsallıktır bu. Marx ile Engels, toplumu ve toplum bilimlerini derinlemesine inceledikçe, diyalektik düşünce biçiminin yol göstericiliğinde, toplumsal yaşamın, dolayısıyla da değişimin devingecini (motorunu) yakalamışlardır. Ulaştıkları görüşe göre, toplumu devindiren, değ iştiren, dönüş̧üren temel çelişki, insanoğlunun ezelden beri karşı karşıya kaldığı, kendi maddi yaşamını yeniden üretme zorunluğunda gizlidir. Bu zorunluk hep var olduğundan, insanoğlunun tüm yaşamı, onnünde sonunda, hep bu temel çelişki tarafından koşullandırılmaktadır.

Tarihsel maddeciliğin bu savı, her zaman açıkça sరylenmese bile, bugün toplumbilimin en yaygın görüşü durumundadır. Bugün artık, toplumsal yaşamda, son çözümlemede, geçimsel zorunlukların egemen olduğunu hemen hemen herkes teslim etmcktedir. Ancak, elbette, bu kadarinı sơlemekle bir bilim dalı kurulmaz. Marx, "tarih . 
bilimi" dedigi toplumbilimin temel çözümleme araçlarını yaratan kişidir. Üretim güçleri, üretim ilişkileri, üretim biçimi, toplumsal sınıflar, altyapı, üstyapı, belirleme, toplumsal kuruluş, vb. gibi kavramlarla, toplumların devinimini ve dönüşümünü, yani kısacası "tarih"i anlamamızı sał̆layacak en verimli kuramı geliştirmiştir.

Buna ek olarak, Marx, zamanının en ileri üretim biçimi olarak en çok ilgi duydugu kapitalist üretim biçimini de incelemiştir. Gerçi bu incelemesini tamamlayamamışur. Bilindiģi gibi, dớr ciltten oluşan Kapital'in yalnızca birinci cildi Marx'ın sağlığında yayınlanmıştır. Öte yandan, Marx'in incelediģi kapitalizm, o günden bu güne çok değişmiştir. Dolayısıyla, Marx'ın incelemesinde, hem birçok eksik, hem de birçok yanlış bulunması doğaldır. Ancak, şu da bir gerçektir ki Kapital, şimdiye dek kapitalist üretim biçimi üzerinde yapılan incelemelerin en başanlı olanlarından biridir.

Bu saptamalardan, Marx ve bilim konusunda, ne gibi sonụçlar çıkarılabilir?

Bir kere, Marx, tüm yaşamı bilimsel çalışma içinde geçmiş, ciddi ve olağanüstü yetenekli bir bilim adamıdır. Bunın en açık kanıu, yeni bir bilim dalı kurmuş olmasıdır. Kendisinin "tarih bilimi" dediği bu dal, aslında toplumbilimdir. Çünkü, bu bilimin konusu, toplumun kendisidir. Marx'tan önce ve sonra, toplumun şu ya da bu yönünü inceleyen bilim dalları çıkmışur. Ancak, şimdiye dek, tüm toplumun devinim ve deģişimini anlamak için, Marx'ınkinden daha açıklayıcı bir kuram geliştirilememiştir.

Ikincisi, bu kuram elbette eksiksiz ve yanlı̧sız degildir. Ancak, Marx'ın kendi kuramını geliştirirken birtakım yanılgılara đüşmüş olması, kurduğu bilim dalını büttünüylü geçersiz saymaya olanak vermez. Freud'ün, ömeğin "ölüm içgüdüsü" gibi birtakım görüşlerinin artık yanlış kabul edilmesi, tinçözümün (psikanalizin) bir bilim dalı olarak onun tarafından kuruldugunun yadsınmasını nasıl hakh kılmazsa, Marx'ın şu ya da bu ơngörüsünün yanlı̧̧ çıkması, toplumbilimin onun tarafından kurulduğu gerçeğinin yadsınmasını haklı gösteremez.

Marx gerçekten bir bilim adamı olarak görülüyorsa, tarihsel maddecilige (ya da toplumbilime) "Marksizm" demekıen vazgeçilmeli, bilimsel bir kuramı "-izm"le nitelendirip onun büyük'yaratıcısına haksızlık edilmemelidir. Aynı şckilde, Marx'ın görüşleri, herhangi bir büyük bilim adamının görüşleri gibi, sınanmalı, tarışılmalı ve asla duygusal bir baghlılık konusu yapılmamalıdır. Bilim adamı olarak Marx'a yappılacak en büyük hizmet, onun kuramını geliştirip aşmaya çalışmaktır. Yoksa, kuramı "inanç konusu" durumuna düşürülmüş bir düşünür, bilim adamı olarak ölmüş demektir.

\section{MARX VE SIYASET}

"Marksizm" nitelemesi, belki yalnrzca bu baģlamda anlamlıdır. Gerçekten de, siyasal savaşıma girdiği andan başlayarak, Marx'in hep sıkı yandaşları ile sıkı hasımları olmuştur. Başka bir deyişle, siyaset sahnesinde birtakım adamlar açıkça "Marx'çı" olmuşlar, birtakım adamlar ise yine açıkça bunlara cephe almışlardır.

Durum bơyle olduğuna göre, Marksizmin bu siyasal boyutuna ilişkin olarak, ne gibi gözlemlerde bulunulabilir?

Bir kere, bu boyutu, felsefe ve bilim boyutlanndan, yani diyalektik maddecilik ile tarihsel maddecilikıen kesinlikle ayırmak gerekir. Birtakım adamların kendilerini 
"Marksist" olarak nitelemeleri, Marx'ın geliştirdił̧i felsefe ve bilim görüşlerini bunların kendilerine mal etmiş olduklan, bu görüşleri gerçekten özümsedikleri anlamına gelmez. $\mathrm{Bu}$ boyuttaki olayların siyasal düzlemde cereyan ettigini, dolayısıyla da felsefe ya da bilim deģil, siyaśet olayları olduklarını gözden kaçırmamak gerekir.

Ikincisi, şu gerçcği önemle vurgulamak gerekir ki, Marx'ın geliştirdiği ve siyasal eylemde Marksistlerin uygulayabilecekleri hazır bir siyaset kuramı yoktur. Başka bir dcyişle, ortada Marx'ın gelişurdiģi bir siyaset bilimi yoktur ki, ona dayanarak "bilimsel bir siyaset" izlencbilsin. Dolayısıyla, Marksistlerin kendi siyasetlerinin bilimsel olduğu savı, bilimsel deģil, siyasal ve düşüngüsel (ideolojik) bir savdır.

Üçüncüsü, Marx ve oun izleyen Marksistler, birer siyaset adamı olarak, siyasal savaşım içinđc hep bir şeyler söylemek, bir şcyleri savunmak, bir şeyler yapmak, yan tutmak zorunda kalmışlardır. Bu da, tüm siyaset adamlan gibi, kaçınılmaz olarak, onların da zaman zaman yanlışlar yapmalarına yol açmıştır. Ancak, Marksist siyasetçilerin şu ya da bu yanlışı yapmış olmalarını, Marx'ın yaratı̆g felsefe ve bilim dalının yanlış olduğunun kanıu olarak ileri sürmck tamamen anlamsızdır.

Dơrdüncüsü, kendilerini "Marksist" diye niteleyen siyaset adamları bulunduğu sürece, siyasetbilimcileri de, bu savın geçerliğini saptama göreviyle karşı karşıya kalacaklardır. Yoksa, siyasal olaỳ ve olgularla ilgili bilimsel çözümlemeleri eksik kalır. Oyleyse, "Kime Marksist denir?", "Kendine Marksist diyen herkes gerçekten Marksist midir?" gibi sorulara yanıt bulmak gerckir. Kanımca, gerçek bir Marksist siyasetçi, kafası diyalektik maddecilikle bilenmiş, tarihsel maddeciliğin sağladı̆̆ı bilgilerle donanmıs olarak, içinde yaşadığı somut durumun verilerine dayanıp olabilecek en yakın zamanda sınıfsız bir toplum kurma creğine ulaşmak için en uygun siyasal tutum ve davranışı benimscyen kişidir. Elbette, bunun da terazisi yoktur. Daima birtakım adamlar birbirlerini kötü Marksist olmakla, ya da Marksist olmamakla, ya da aksine Marksist olmakla suçlayacaklardır. Kimin haklı olduğunu, ancak daha sonra tarihi yazanlar belirleyebileceklerdir.

\section{SONUÇ}

Marksizm hem felsefedir, hem bilimdir, hem de siyaset ve düşüngüdür. Bu yönleri birbirine kanş̧ırılırsa, konuyu anlama olanağı ortadan kalkar.

Marx ile Engels'in önayak oldukları diyalektik maddecilik, çökmek bir yana, her geçen gün yaygınlık kazanmaktadır. Çünkü, kendi gelişimini bilimlerinkine baglamışur. Bilimler geliştikçe, o da bir tür ortak saģduyu durumuna gelmektedir.

Yine Marx ile Engels'in yarattıkları tarihsel maddecilik, toplumú bir bütün olarak açıklamak için bugüne dek geliştirilmiş olan en doyurucu kuram olarak kalmıştır. Bilimsel bir kuramın, siyasal uygulamalarla dogrulanması ya da yanlışlanması beklenemez. Marx'ın adına bağlı olan toplumbilim, ancak onu da açıklayacak, ondan daha kapsamlı ve doyurucu bir bilimsel kuramla aşılabilir. Ne yazık ki, bilim adamları bunu ' henüz başaramamışlardır.

Başta Marx'ın kendisi olmak üzere Marksistlerin geliştirdikleri kimi siyasal gorüşler, tutumlar ve davranışlar, zaman içinde birçok kez yanlıs çıkmıştır. Sosyalist devlet yönctiçilcrinin ise, kendi düzenlerini yıkacak ơlçüde büyük yanlışlar yaptıkları 
ortadadır. Ne var ki, Marksisılerin yaptıkları bütïn yanlışların faturasını Marx'a çıkarmak da anlamsızdır. Siyaset olan her yerde yanılgı vardır. Marksisuler bundan sonra da çok yanilacaklardır.

Ayrıca, hasımlarının bu yanlışları düşüngüsel (idcolojik) savaş gereci olarak kullanmaları da dogaldır. Bu türden kolaycı "kanıları", Marksistler de çok kullanmışlardır. Düşüngüsel savaşın kuralı budur.

Ancak, konuya bilimsel bir sogukkanlılıkla yaklaşanlar, bu duruma ne sevinirler, ne de kızarlar. Bilirler ki, örneğin bir yapının yıkılması, illa da dayanılan mimarlık kuramının yanhıs olduğunu kanıllamaz. Mimar beceriksizlik yapmış olabilir, kullanılan gereçler elverişsiz olabilir, ya da yapının oturtuldugu yer, önceden kestirilemeyecek olçüde kaymış olabilir. Tck bir olasılığa saplanmadan, ancak hiçbir olasılığı baştan reddetmeden, araşurmayı ve düşünmeyi sürdürmckıen başka çıkar yol yoktur. 